\title{
BMJ Open What are the decision-making preferences of patients in vascular surgery? A mixed-methods study
}

\author{
T B Katrien Santema, ${ }^{1}$ E Anniek Stoffer, ${ }^{2}$ Marleen Kunneman, ${ }^{2}$ \\ Mark J W Koelemay, ${ }^{1}$ Dirk T Ubbink ${ }^{1}$
}

To cite: Santema TBK, Stoffer EA, Kunneman M, et al. What are the decisionmaking preferences of patients in vascular surgery? A mixed-methods study. BMJ Open 2017;7: 013272 . doi:10.1136/bmjopen-2016013272

- Prepublication history for this paper is available online To view these files please visit the journal online (http://dx.doi.org/10.1136/ bmjopen-2016-013272).

Received 30 June 2016 Revised 8 October 2016 Accepted 27 October 2016

CrossMark

\begin{abstract}
${ }^{1}$ Department of Surgery, Academic Medical Center, Amsterdam, The Netherlands ${ }^{2}$ Department of Medical Psychology, Academic Medical Center, Amsterdam, The Netherlands
\end{abstract}

Correspondence to TB Katrien Santema; t.b.santema@amc.uva.nl

\section{ABSTRACT}

Objectives: Shared decision-making (SDM) has been advocated as the preferred method of choosing a suitable treatment option. However, patient involvement in treatment decision-making is not yet common practice in the field of vascular surgery. The aim of this mixed-methods study was to explore patients' decision-making preferences and to investigate which facilitators and barriers patients perceive as important for the application of SDM in vascular surgery.

Design and setting: Patients were invited to participate after visiting the vascular surgical outpatient clinic of an Academic Medical Center in the Netherlands. A treatment decision was made during the consultation for an abdominal aortic aneurysm or peripheral arterial occlusive disease. Patients filled in a number of questionnaires (quantitative part) and a random subgroup of patients participated in an indepth interview (qualitative part).

Results: A total of 67 patients participated in this study. 58 per cent of them $(n=39)$ indicated that they preferred a shared role in decision-making. In more than half of the patients $(55 \% ; n=37)$ their preferred role was in disagreement with what they had experienced. 31 per cent of the patients $(n=21)$ preferred a more active role in the decision-making process than they had experienced. Patients indicated a good patient-doctor relationship as an important facilitator for the application of SDM.

Conclusions: The vast majority of vascular surgical patients preferred, but did not experience a shared role in the decision-making process, although the concept of SDM was insufficiently clear to some patients. This emphasises the importance of explaining the concept of SDM and implementing it in the clinical encounter.

\section{INTRODUCTION}

Shared decision-making (SDM) and patient involvement in the clinical encounter is on the rise. ${ }^{1}$ SDM had been defined by Elwyn et $a l^{2^{3}}$ as 'an approach where clinicians and patients share the best available evidence when faced with the task of making decisions, and where patients are supported to

\section{Strengths and limitations of this study}

- A mixed-methods study was used to explore patients' decision-making preferences. This enabled us to qualitatively explore patients' reasons and ideas behind their responses to the shared decision-making (SDM) questionnaires.

- This study provides valuable information about facilitators and barriers patients perceive as important for the application of SDM in vascular surgery.

- Post hoc justification, in terms dwindling symptoms or satisfaction with the treatment result and the desire to justify prior decisions as the right one, may have altered the patients' opinion about SDM preferences.

- Caution is needed in generalising the findings of this study, due to our relatively small patient sample.

consider options, to achieve informed preferences'. The SDM approach takes position between a paternalistic model in which the 'doctor knows best' and a consumer model in which the patient selects his preferred treatment after the clinician has offered information about the treatment options. ${ }^{4-6}$

Patient involvement in treatment decisionmaking and the use of decision aids to encourage or facilitate SDM have been shown to increase patient satisfaction and disease knowledge. ${ }^{7} 8$ Furthermore, SDM increases the likelihood that patients receive treatments that are consistent with their personal values. This may reduce overtreatment, increase treatment adherence and improve health outcomes. ${ }^{9-13}$

In vascular surgery, there are often multiple viable treatment options, making this decision preference-sensitive. For patients with an abdominal aortic aneurysm (AAA), viable options are observation, open surgery or endovascular repair. ${ }^{14}$ In patients with peripheral arterial occlusive disease (PAOD), the options are either exercise training, 
angioplasty or bypass surgery. ${ }^{15}$ In such preferencesensitive treatment decisions, the weighing of harms and benefits depends on the patients' individual preferences. ${ }^{16}$ Patient involvement is therefore fundamental in making a decision about which treatment option best fits the patient's situation, goals and values. Nevertheless, patient involvement in treatment decisionmaking is not yet common practice in the field of vascular surgery. ${ }^{17}$ Clinicians often indicate to believe that patients do not want to participate in the decisionmaking process. ${ }^{18}{ }^{19}$ Awareness is burgeoning among vascular surgeons that the effects of vascular surgical interventions may require deliberation with their patients, especially when considering possible undesired but serious adverse outcomes, ${ }^{20}{ }^{21}$ but the extent to which patients want to participate in the treatment decision-making is still unclear. Furthermore, little is known about factors patients feel are important for their involvement in the process of decision-making. The aim of this study was therefore to explore the patients' decision-making preferences and to investigate which facilitators and barriers patients perceive as important for the application of SDM in vascular surgery.

\section{METHODS}

We used a mixed quantitative (questionnaires) and qualitative (interviews) approach. An embedded mixedmethods design enabled us to integrate the quantitative and qualitative data. ${ }^{22}$ In this study, the qualitative outcomes were used for clarification and exploration of the quantitative outcomes. For the design and execution of the qualitative part of this study, we used the Consolidated Criteria on Reporting Qualitative Research (COREQ) checklist. $^{23}$

\section{Study participants}

We invited consecutive patients with AAA and PAOD after they had visited the vascular outpatient clinic of the Academic Medical Center, one of eight Dutch university hospitals, between June and November 2015. Patients were invited through an invitation letter accompanied by a postal questionnaire within 3 months after the consultation, so that patients could still recall the encounter. We excluded patients who were unable to complete questionnaires in Dutch or were not compos mentis (to the discretion of the treating vascular surgeon). We invited patients until a convenience sample of 60 participants was created. Patients filled in the questionnaires alone or with the help of a psychologist who was not involved in the treatment of the patient.

A random subgroup of participating patients who completed the postal questionnaire was invited by telephone for an additional qualitative, semistructured interview. The sampling for this interview was based on gender and health condition in order to create a subgroup that was similar to the overall cohort of participating patients. However, the selection was blinded for all other patient characteristics and questionnaire answers. Patients were guaranteed that the data collected were handled anonymously. They were asked beforehand to consent with digital audio-recording of the interviews.

\section{Quantitative part (questionnaires)}

All patients were asked to provide brief demographic details and to complete the Control Preferences Scale (CPS),$^{24}$ the Ideal Patient Autonomy Scale (IPAS) ${ }^{25}$ and the 9-item Shared Decision Making Questionnaire $\left(\right.$ SDM-Q-9) ${ }^{26}$ and CollaboRATE questionnaires. ${ }^{27} 28$

The original CPS consists of vignettes, each with a statement and a cartoon that portrays the five different roles in the decision-making process. We used a modified version of the CPS to assess both the patients' preferred and their experienced role in the decision-making process by selecting one of five roles: (1) I prefer to make the decision alone, (2) I prefer to make the decision after seriously considering my surgeon's opinion, (3) I prefer that my surgeon and I share responsibility for deciding which treatment is best for me, (4) I prefer that my surgeon makes the final decision after seriously considering my opinion and (5) I prefer that my surgeon makes the decision alone (figure 1). ${ }^{24}$ 29-31

To assess a patient's ideal level of autonomy in the deliberation with a doctor in general, we used the IPAS. This questionnaire consists of 14 statements that are scored on a five-point Likert scale, ranging from 1 (completely disagree) to 5 (completely agree) which we recoded into three categories (scores 1 or 2, disagree; score 3 , neutral; scores 4 or 5 , agree; see table 2 , first column). ${ }^{25}$

For the assessment of the current practice of SDM as evaluated by the patients, we used the SDM-Q-9 and the CollaboRATE instruments (shown in table 3). The SDM-Q-9 assesses patients' experiences with nine steps of the decision-making process on a six-point Likert scale, ranging from 1 (completely disagree) to 6 (completely agree) ${ }^{26}$ CollaboRATE is a brief, three-item measure that specifically assesses how much effort was made by the surgeon on three core elements of SDM, and is rated by the patient on a 10-point Likert scale, ranging from 1 (no effort was made) to 10 (every effort was made). ${ }^{27} 28$

\section{Qualitative part (interviews)}

All interviews were conducted by EAS, a trained psychologist, and discussed afterwards with TBKS, a medical doctor and researcher. The interviews took place face-to-face at the hospital or via telephone, whichever the patient preferred. We aimed to conduct interviews until we reached saturation, that is, no new arguments or topics were brought up, with a minimum of 10 interviews. $^{32}$ 


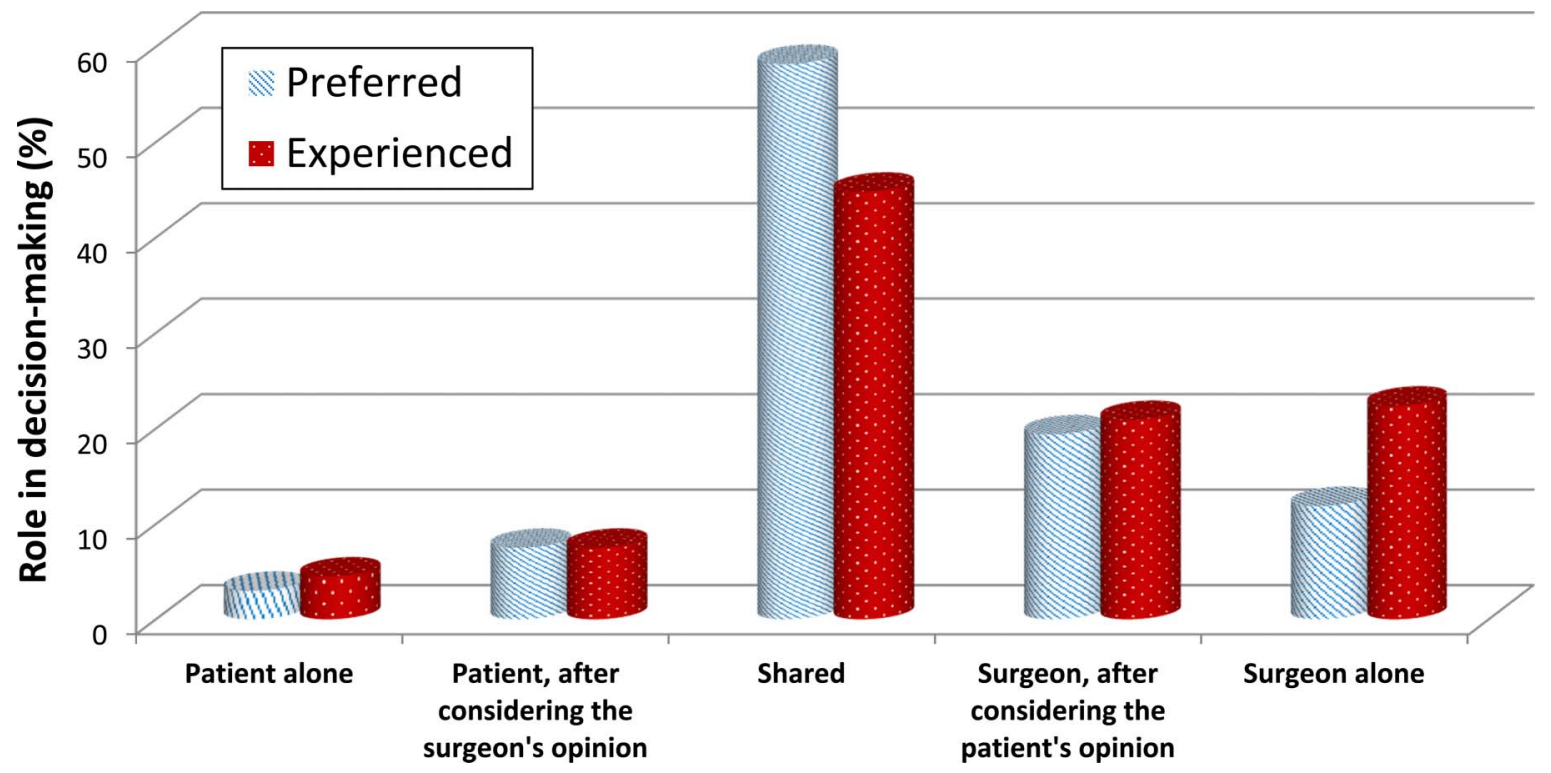

Figure 1 Patients' preferred and experienced role in decision-making.

\begin{tabular}{lc} 
Table 1 Patient characteristics & \\
\hline & N=67 (\%) \\
\hline Age, years (SD; range) & $68.9(9.4 ; 43-92)$ \\
Gender, male & $52(78)$ \\
Disease & \\
Peripheral arterial disease & $33(49)$ \\
Abdominal aortic aneurysm & $27(40)$ \\
Both & $7(10)$ \\
Marital status & \\
Married or living with partner & $43(64)$ \\
Widowed & $12(18)$ \\
Single & $7(10)$ \\
Divorced & $5(8)$ \\
Educational level & \\
Low or intermediate* & $54(81)$ \\
High $\dagger$ & $13(19)$ \\
*Primary school, secondary education or intermediate vocational \\
education. \\
†Higher vocational education.
\end{tabular}

The postal questionnaire the patients had completed was used as the framework for the interview. In-depth interviewing enabled us to discover the patients' motives for the quantitative part of this study. In addition, we explored the patients' facilitators and barriers to SDM with two open-ended questions: (1) 'Which factors do you consider facilitators or motivators for you to be more involved in the decision-making process?', and (2) 'Which factors do you consider as barriers or preventing factors for you to be involved in the decision-making process?'

\section{Analysis}

Statistical analyses of quantitative measures were performed using the Statistical Package for the Social Sciences V.22 (IBM/SPSS, Armonk, New York, USA). We presented descriptive statistics as means or medians with SDs or IQR, respectively, for continuous variables or as a count with percentages for categorical variables.

Recordings of the semistructured interviews were transcribed non-verbatim, except for fragments containing patients' decision-making preferences or factors that patients perceived as facilitators for or barriers to the involvement in SDM, which were transcribed verbatim. Patients' responses were coded independently by two investigators (TBKS and EAS) on a predefined interview extraction sheet. Coding was performed both deductively and inductively, with predefined codes based on topics from the SDM questionnaire and new codes derived from the interview data. ${ }^{33}$ Any discrepancies between coding were resolved by consensus.

\section{RESULTS}

Out of the 100 patients who were invited to participate in this study, 67 agreed and completed the questionnaires. Being typical for this patient population, the patient sample included mostly men $(n=52 ; 78 \%)$ as shown in table 1.

Seventeen patients were interviewed, of whom 14 $(82 \%)$ were men. Mean age among the interviewed patients was 71.8 years (SD 9.3; range 51-92 years). Seven of them were diagnosed with an AAA, seven with PAOD and three with both.

The results of the questionnaires and interviews are presented jointly below.

\section{Preferred and experienced level of SDM (CPS)}

The patients' preferred and experienced levels of SDM are summarised in figure 1 . Most patients $(58 \% ; n=39)$ indicated they preferred a shared role in decisionmaking, while 7 (10\%) indicated they would even prefer 
Table 2 Ideal Patient Autonomy Scale

\begin{tabular}{|c|c|c|c|}
\hline Statement & $\begin{array}{l}\text { Disagree } \\
(\%)\end{array}$ & $\begin{array}{l}\text { Neutral } \\
(\%)\end{array}$ & $\begin{array}{l}\text { Agree } \\
(\%)\end{array}$ \\
\hline $\begin{array}{l}\text { 1. If the patient does not want to receive information about risks, the doctor should } \\
\text { respect this. }\end{array}$ & 25 (37.3) & $11(16.4)$ & $31(46.3)$ \\
\hline 2. It is better that the doctor rather than the patient decides which the best treatment is. & $8(11.9)$ & $6(9.0)$ & $53(79.1)$ \\
\hline 3. The patient has to be informed on all the risks involved in an operation. & $4(6.0)$ & & $63(94.0)$ \\
\hline 4. Patients should have the right not to be involved in the decision on the treatment. & $35(52.2)$ & $5(7.5)$ & $27(40.3)$ \\
\hline $\begin{array}{l}\text { 5. During the conversation, the patient must submit himself with confidence to the } \\
\text { expertise of the doctor }(n=66) \text {. }\end{array}$ & $6(9.1)$ & $5(7.6)$ & 55 (83.3) \\
\hline 6. The patient himself must choose between the various treatments. & $17(25.4)$ & $14(20.9)$ & $36(53.7)$ \\
\hline $\begin{array}{l}\text { 7. Before a patient consents to a treatment he should receive all information on the } \\
\text { risks involved. }\end{array}$ & $2(3.0)$ & $2(3.0)$ & 63 (94.0) \\
\hline $\begin{array}{l}\text { 8. Patients who become afraid when thinking about the treatment decision should be } \\
\text { left in peace by the doctor. }\end{array}$ & $19(28.4)$ & $15(22.4)$ & 33 (49.3) \\
\hline $\begin{array}{l}\text { 9. If doctor and patient cannot agree on which treatment is best, the doctor should } \\
\text { take the final decision. }\end{array}$ & 21 (31.3) & $8(11.9)$ & $38(56.7)$ \\
\hline $\begin{array}{l}\text { 10. The patient should, without much information on the risk involved, confidently } \\
\text { undergo an operation. }\end{array}$ & $20(29.9)$ & $7(10.4)$ & $40(59.7)$ \\
\hline 11. It goes too far when the doctor decides which treatment is best for the patient. & $23(34.3)$ & $10(14.9)$ & $34(50.7)$ \\
\hline $\begin{array}{l}\text { 12. The doctor can presume that the patient knows that people can die during } \\
\text { serious operations. }\end{array}$ & $19(28.4)$ & $5(7.5)$ & $43(64.2)$ \\
\hline $\begin{array}{l}\text { 13. If a patient chooses a treatment with more health risks, the doctor should respect } \\
\text { this treatment decision. }\end{array}$ & $9(13.4)$ & $10(14.9)$ & 48 (71.6) \\
\hline 14. As it concerns the body and life of the patient, the patient should decide. & $14(20.9)$ & $12(17.9)$ & $41(61.2)$ \\
\hline
\end{tabular}

a leading role (making the decision alone or after considering the doctors' opinion).

In more than half of the patients $(55 \% ; n=37)$ their preferred role was in disagreement with the role they had experienced: $31 \% \quad(\mathrm{n}=21)$ preferred more involvement in the decision-making process than experienced, while $24 \% \quad(n=16)$ preferred less involvement than experienced. Four out of the seven patients who preferred a leading role $(57 \%)$ indicated that they experienced the opposite; that is, the surgeon made the treatment decision.

Patients who preferred a shared process frequently indicated that the decision-making was based on equality and sincerity:

I want to know everything. The doctor must inform me, but I also search on the internet. It is my task to ask questions whenever it is not clear to me. It is my body, but the doctor is the expert so we should make the decision together, but as long as my mind is clear, I will make the final decision. Patient \#2; a 69-year-old man diagnosed with an AAA

I want to discuss what is best for me. The surgeon is the expert and must be honest about the risks. Things that are feasible and things that are not. And I want an advice. But the concerns and wishes of the patient must be included. However, some things are impossible for the doctor. They [doctor and patient] should help each other. The information must come from both sides. Patient \#13; a 74-year-old man diagnosed with an AAA

Other patients stated they did not want to be involved in decision-making due to their unfamiliarity with the
SDM concept. Moreover, patients often referred to the final decision rather than the decision-making process itself:

I am very happy when the surgeon is explaining all the things about risks and stuff, but ultimately I assume the doctor will make the right decision for me. Patient \#9; an 80-year-old man diagnosed with an AAA and PAOD

I am a lay person. I prefer to leave it to that person who knows the most about it, the expert. They have studied for it and they are experienced. What can I add to that? Patient \#11; a 92-year-old woman diagnosed with PAOD

Some patients want their surgeon to make a decision, but to a limited extent:

Together? I mean, haha. When the doctor says you need this treatment, how can I say, no doc, that is ridiculous! Haha, no I can't. No, when the doctor says this treatment is the best for me, I will do that [but later on during the interview]: No, when the doctor wants all kinds of invasive treatments, no then I will refuse it, despite his good intentions, No, I do not feel like it. Patient \#12; an 80-year-old man diagnosed with PAOD.

\section{Patient autonomy (IPAS)}

IPAS scores are shown in table 2. Four of the statements in the IPAS questionnaire (items 2, 5, 9 and 10) gauge whether patients think that the doctor should decide or knows best. The majority of patients agreed with these statements $(57-83 \%)$.

However, when interviewing patients about the underlying thoughts on these statements there were, again, 
Table 3 Questionnaires about the patients' appreciation of the current practice of SDM

\begin{tabular}{|c|c|c|}
\hline \multicolumn{2}{|c|}{ SDM-Q-9 items } & \multirow{2}{*}{$\begin{array}{l}\text { Median (IQR) } \\
6(3-6)\end{array}$} \\
\hline Item 1 & Clarifying a decision needs to be made & \\
\hline Item 2 & Eliciting the patients' preferred involvement & $5(2-6)$ \\
\hline Item 3 & Stating there is more than one way to deal with the problem & $5(1-6)$ \\
\hline Item 4 & Explaining pros and cons of treatment options & $5(4-6)$ \\
\hline Item 5 & Investigating whether the patient has understood all the information & $6(5-6)$ \\
\hline Item 6 & Identifying the patients' preferred treatment option & $4(1-6)$ \\
\hline Item 7 & Weighting the treatment options & $4(1-6)$ \\
\hline Item 8 & Making a shared decision & $4(2-6)$ \\
\hline Item 9 & Agreement on follow-up arrangements & $5(4-6)$ \\
\hline \multicolumn{2}{|c|}{ CollaboRATE items } & Median (IQR) \\
\hline Item 1 & How much effort was made to help you understand your health issues? & $8(8-10)$ \\
\hline Item 2 & How much effort was made to listen to the things that matter most to you about your health issues? & $8(8-10)$ \\
\hline Item 3 & How much effort was made to include what matters most to you in choosing what to do next? & $8(8-10)$ \\
\hline
\end{tabular}

two ways in which patients interpreted these statements. In the first, the patient usually meant that the medical expertise of the surgeon is necessary for making the final decision, but with the involvement of the patient. In the second, patients agreed with these statements because the surgeons' medical expertise precluded patients from participating in the decision-making process.

The doctor gives you an advice. He is an expert so it is likely that I will agree with that. Patient \#10; a 79-year-old man diagnosed with an AAA

The doctors can decide, but do I have a voice? It is my body! Patient \#14; a 59-year-old woman diagnosed with PAOD

Four IPAS statements are about the patient who should decide (items 6, 11, 13 and 14). Again, the majority of the patients agreed with these statements $(51-72 \%)$.

Yes, I totally agree on that! [item 11]. They should also listen to me. I am the patient. It is my body. I say what is going to happen, not the doctor! If they need to take something out, I make that decision! Patient \#13; a 74-year-old man diagnosed with an AAA

Three IPAS statements focus on the right not to participate (items 1, 4 and 8). The patients' opinions diverged on this theme. A number of patients agreed with the right not to receive information or not to be informed (40-49\%). Many of them stated this is a personal issue and it is always the right of the patient not to be informed. However, a substantial proportion of patients did not agree (28-52\%) and thought that patients should always be involved or at least informed.

Hmm, I am not sure about that [item 1]...When a patient explicitly says he doesn't want to know... Ok, yes, then I agree on that. But the doctor should at least ask why he does not want to know. But in general, the doctor may assume that a patient wants to know. Patient \#6; a 79-year-old man diagnosed with an AAA.

No, I don't agree on that [item 1]. That is ridiculous! When you go to the hospital with a request for help, you should know this visit has consequences. When you don't want to know, then you should not visit the hospital and stay home. Patient \#1; a 63-year-old man diagnosed with PAOD

The remaining three IPAS statements address risk information (items 3, 7 and 12). The great majority of patients indicated that patients should receive all information about possible risks (46-94\%). Most patients agreed on the statements that the doctor can presume that the patient is aware of the fact that people can die during serious operations. However, patients frequently stated that doctors should always inform the patient about these risks.

Yes, he may assume I know the risk but he should explicitly state this. Patient \#9; an 80-year-old man diagnosed with an AAA and PAOD

\section{Current practice (SDM-Q-9 and CollaboRATE)}

As shown in table 3, the median SDM-Q-9-scores among the patients were high. The highest median scores were found for item 1, 'clarifying a decision needs to be made', and item 5, 'investigating whether the patient has understood all the information'. Lower median scores were found on items 6 (patients' preference), 7 (weighting options) and 8 (shared decision). Scores on the CollaboRATE questionnaire were high, with similar scores for all three items (median 8, IQR 8-10).

From the answers patients gave during the interviews, we learnt that the items within the SDM-Q-9 and CollaboRATE questionnaires were not always interpreted and rated in terms of SDM, but rather as general satisfaction with the consultation. Furthermore, some patients indicated that they were well informed (SDM-Q-9 item 4 
was rated with a median score of 5), while during the interviews patients frequently stated they did not receive much information about the practical aspects of the admission or consequences of the procedures.

Yes, he did! [CollaboRATE item 1, patient rated this item with a nine out of ten points] I received a brochure and I could extract a lot out of it. And I could ask questions. Patient \#6; a 79-year-old man diagnosed with an AAA

The following patient gave the maximum score for all SDM-Q-9 items:

I knew physical therapy would take more time than surgery. But I did not know that I would need additional visits to the hospital after the surgery...I thought I was done then. But after the surgery I heard that I had to come back for additional visits. And that I need the use pills for the rest of my life...I did not know that. Patient \#14; a 59-year-old woman diagnosed with PAOD

A few hours after the operation I was allowed to go home. Home! I did not know that! They told me I would get an adhesive plaster and then go back to the ward. But home? No, I thought that I had to stay overnight. Patient \#5; a 67-year-old man diagnosed with an AAA

\section{Facilitators and barriers to SDM}

We asked patients which facilitators would make patients more likely to be involved in the decision-making process. Frequently mentioned were: trust in the doctor, a clear communication style of the doctor, enough time for the consultation and a doctor who is really listening to the patient.

When you are undergoing surgery, you should surrender. Those doctors have learned for it and you have to rely on them. Patient \#12; an 80-year-old man diagnosed with PAOD

Honesty and trust. I am a lay person, but when I am not heard, then I think: why did this doctor choose this career? They have to be honest and should not prevaricate. Patient \#14; a 59-year-old woman diagnosed with PAOD

Some patients mentioned facilitators that were attributable to the patients themselves.

I think a patient should prepare. When you are prepared and informed you are more relaxed. In my opinion it is also the responsibility of the patient. Patient \#15; a 73-year-old woman diagnosed with PAOD

Barriers for patient involvement that were mentioned were a non-equal relationship with the surgeon, no clear communication, different doctors over time, a lack of continuity of care and a surgeon who is poorly informed or ill prepared for the consultation.

When there is a distance between the patient and the doctor, that is a barrier. Or too much information or too quickly. And a lot of technical information... Doctors that think they are God. In the past... Older people may think the doctor knows best. But nowadays patients are more assertive. That is better for the patient. The new generations of doctors should be aware of that. Patient \#7; a 74-year-old woman diagnosed with PAOD

\section{Discussion and conclusion}

The aim of this mixed-methods study was to explore patients' decision-making preferences and to investigate which facilitators and barriers patients perceive as important for the application of SDM in vascular surgery. We found that a significant number of vascular surgical patients prefer a shared role in the decisionmaking process, while they did not experience their desired level of SDM during the decision-making consultation with their surgeon.

Some patients indicated they rather not want to be involved in deciding about treatment, but this frequently referred to making the final decision. However, leaving the final decision to the surgeon should not be confused with being unwilling to participate in the decisionmaking process. Whether or not the patient defers the final decision to the surgeon, patient's values should be discussed and considered when choosing a treatment strategy. This increases the likelihood that patients receive a treatment that is consistent with their personal values and preferences. Even though some patients may want to leave the final treatment decision to their surgeon, the following three steps are recommended for all consultations in which treatment options are discussed: (1) creating choice awareness (choice talk), (2) discussing treatment options (option talk), and (3) discussing the patients' preferences and making a decision (decision talk). ${ }^{2}$

Patients gave high scores for the current SDM practice. This is in accordance with our previously conducted study, ${ }^{17}$ and could possibly be caused by the unfamiliarity with the SDM concept among patients. Also during the interviews we discovered that patients erroneously used the SDM questionnaires to express their general satisfaction with the consultation or their care. Furthermore, patients scored high on item 1 of the SDM-Q-9 questionnaire (clarifying a decision needs to be made) but previous research found that clinicians rarely express explicitly that a decision needs to be made. ${ }^{1734} 35$ Therefore, the concept and the steps of SDM should be clear to patients before they can reliably score the perceived level of SDM. Importantly, our combined quantitative and qualitative findings on patients' preferred and perceived involvement in decision-making raise the question whether we really know what we are currently measuring with self-reported SDM levels or patient involvement questionnaires. Furthermore, others have already shown that observer-based SDM scores were not always consistent with patient-reported SDM scores. ${ }^{36}{ }^{37}$ The unfamiliarity of patients with the concept of SDM should be taken into account in developing and validating future instruments to measure SDM. 
In this study, relatively low scores were found for SDM-Q-9 items 6 (patients' preference), 7 (weighting options) and 8 (shared decision). This implies that treatment decision-making is currently limited to informing the patient, which has been found in earlier research as well. ${ }^{17} 38$ Identifying and incorporating patients' treatment preferences is not yet common practice. Hence, surgeons should actively invite patients to share their goals, expectations and concerns to prevent the misdiagnosis of patient preferences. ${ }^{39}$

Patients considered a good patient-doctor relationship (trust, honesty, equity) as a pre-requisite for the application of SDM. In contrast, earlier research has shown that the healthcare professionals appear to have a quite different perspective. A systematic review by Légaré $e t a l^{19}$ found that besides provider motivation, positive impact on the clinical process and patient outcomes were the main facilitators for SDM. Time constrains, patient characteristics and the clinical situation were the most frequently reported barriers to SDM. Of these barriers, patients in our study only mentioned time constraints. Another important barrier for the application of SDM in vascular surgery that was mentioned was a non-equal relationship with the surgeon. Apparently, patients see other reasons not to engage in SDM than doctors do. The patient-doctor relationship was also a predominant theme in the review performed by Joseph-Williams et $a l^{40}$ They conclude that patients need power and knowledge to participate in SDM.

We found that patients frequently consider themselves as lay persons and look at the surgeon as the expert who should make the final decision. Although patients are not medically trained, we believe it is important that they realise they are experts in terms of their personal preferences regarding the treatment options and possible outcomes. ${ }^{41}$ Therefore, they have an important role in the decision-making process. This is particularly relevant in vascular surgery, where some invasive procedures may lead to serious complications. ${ }^{15}$

\section{CONCLUSION}

This study adds the patients' perspective to the existing knowledge from previous reports, showing that vascular surgeons can improve on their communication of possible benefits and harms of their interventions, ${ }^{21}$ and that present vascular surgical consultations still have a low level of SDM. ${ }^{17}$ For successful implementation of SDM in the field of vascular surgery, it is important that surgeons are aware of the desire of most patients to participate in treatment decision-making. Surgeons can prepare their patients for their role in decision-making by explaining the concept and process of SDM.

Twitter Follow Marleen Kunneman @MarleenKunneman

Acknowledgements The authors are very grateful to the patients who participated in this study. Furthermore, the authors also thank the vascular surgeons (in training) of the Academic Medical Center, Amsterdam, for their help with the patient recruitment.
Contributors TBKS, EAS, MK, MJWK and DTU were involved in study conception and design. TBKS and EAS were involved in acquisition of data. TBKS, EAS, MK, MJWK and DTU were involved in analysis and interpretation of data. TBKS was involved in drafting of manuscript. EAS, MK, MJWK and DTU were involved in critical revision of the manuscript.

Funding This research received no specific grant from any funding agency in the public, commercial or not-for-profit sectors.

\section{Competing interests None declared.}

Ethics approval Institutional Review Board of the Academic Medical Center, Amsterdam.

Provenance and peer review Not commissioned; externally peer reviewed.

Data sharing statement No additional data are available.

Open Access This is an Open Access article distributed in accordance with the Creative Commons Attribution Non Commercial (CC BY-NC 4.0) license, which permits others to distribute, remix, adapt, build upon this work noncommercially, and license their derivative works on different terms, provided the original work is properly cited and the use is non-commercial. See: http:// creativecommons.org/licenses/by-nc/4.0/

\section{REFERENCES}

1. Stiggelbout AM, Van der Weijden T, De Wit MP, et al. Shared decision making: really putting patients at the centre of healthcare. BMJ 2012;344:e256.

2. Elwyn G, Frosch D, Thomson R, et al. Shared decision making: a model for clinical practice. J Gen Intern Med 2012;27:1361-7.

3. Elwyn G, Laitner S, Coulter A, et al. Implementing shared decision making in the NHS. BMJ 2010;341:c5146.

4. Charles C, Gafni A, Whelan T. Shared decision-making in the medical encounter: what does it mean? (or it takes at least two to tango). Social Sci Med 1997;44:681-92.

5. Coulter A. Partnerships with patients: the pros and cons of shared clinical decision making. J Health Serv Res Policy 1997;2:112-21.

6. Emanuel EJ, Emanuel LL. Four models of the physician-patient relationship. JAMA 1992;267:2221-6.

7. Knops AM, Legemate DA, Goossens A, et al. Decision aids for patients facing a surgical treatment decision: a systematic review and meta-analysis. Ann Surg 2013;257:860-6.

8. Stacey D, Bennett CL, Barry MJ, et al. Decision aids for people facing health treatment or screening decisions. Cochrane Database Syst Rev 2014;(1):CD001431.

9. Griffin SJ, Kinmonth AL, Veltman MW, et al. Effect on health-related outcomes of interventions to alter the interaction between patients and practitioners: a systematic review of trials. Ann Fam Med 2004;2:595-608.

10. Oshima Lee E, Emanuel EJ. Shared decision making to improve care and reduce costs. N Engl J Med 2013;368:6-8.

11. Hack TF, Degner LF, Watson P, et al. Do patients benefit from participating in medical decision making? Longitudinal follow-up of women with breast cancer. Psychooncology 2006;15:9-19.

12. Naik AD, Kallen MA, Walder A, et al. Improving hypertension control in diabetes mellitus: the effects of collaborative and proactive health communication. Circulation 2008;117:1361-8.

13. Wilson SR, Strub P, Buist AS, et al. Shared treatment decision making improves adherence and outcomes in poorly controlled asthma. Am J Respir Crit Care Med 2010;181:566-77.

14. Moll FL, Powell JT, Fraedrich G, et al. Management of abdominal aortic aneurysms clinical practice guidelines of the European society for vascular surgery. Eur J Vasc Endovasc 2011;41:S1-S58.

15. Norgren L, Hiatt WR, Dormandy JA, et al. Inter-Society Consensus for the Management of Peripheral Arterial Disease (TASC II). Eur J Vasc Endovasc 2007;33(Suppl 1):S1-75.

16. Faggioli G, Scalone L, Mantovani LG, et al. Preferences of patients, their family caregivers and vascular surgeons in the choice of abdominal aortic aneurysms treatment options: the PREFER study. Eur J Vasc Endovasc 2011;42:26-34.

17. Santema TB, Stubenrouch FE, Koelemay MJ, et al. Shared decision making in vascular. Surgery: an exploratory study. Eur J Vasc Endovasc 2016;51:587-93.

18. Légaré $F$, Witteman HO. Shared decision making: examining key elements and barriers to adoption into routine clinical practice. Health Affairs 2013;32:276-84.

19. Légaré F, Ratte S, Gravel K, et al. Barriers and facilitators to implementing shared decision-making in clinical practice: update of 
a systematic review of health professionals' perceptions. Patient Educ Couns 2008;73:526-35.

20. Siracuse JJ, Meltzer EC, Gill HL, et al. Outcomes and risk factors of cardiac arrest after vascular surgery procedures. J Vasc Surg 2015;61:197-202.

21. Knops AM, Ubbink DT, Legemate DA, et al. Information communicated with patients in decision making about their abdominal aortic aneurysm. Eur J Vasc Endovasc 2010;39:708-13.

22. Creswell JW, Olano Clark VL. Designing and conducting mixed methods research. 2nd edn. USA: Sage Publications, 2011.

23. Tong A, Sainsbury P, Craig J. Consolidated criteria for reporting qualitative research (COREQ): a 32-item checklist for interviews and focus groups. Int J Qual Health Care 2007;19:349-57.

24. Degner LF, Sloan JA, Venkatesh P. The control preferences scale. Can J Nurs Res 1997;29:21-43.

25. Stiggelbout AM, Molewijk AC, Otten W, et al. Ideals of patient autonomy in clinical decision making: a study on the development of a scale to assess patients' and physicians' views. J Med Ethics 2004;30:268-74.

26. Kriston L, Scholl I, Holzel L, et al. The 9-item Shared Decision Making Questionnaire (SDM-Q-9). Development and psychometric properties in a primary care sample. Patient Educ Couns 2010;80:94-9.

27. Elwyn G, Barr PJ, Grande SW, et al. Developing CollaboRATE: a fast and frugal patient-reported measure of shared decision making in clinical encounters. Patient Educ Couns 2013;93:102-7.

28. Barr PJ, Thompson R, Walsh T, et al. The psychometric properties of CollaboRATE: a fast and frugal patient-reported measure of the shared decision-making process. J Med Internet Res 2014;16:e2.

29. Henrikson NB, Davison BJ, Berry DL. Measuring decisional control preferences in men newly diagnosed with prostate cancer.

$J$ Psychosoc Oncol 2011;29:606-18.

30. Scholl I, Koelewijn-van Loon M, Sepucha K, et al. Measurement of shared decision making - a review of instruments. Z Evid Fortbild Qual Gesundhwes 2011;105:313-24.
31. Salkeld G, Solomon M, Short L, et al. A matter of trust-patient's views on decision-making in colorectal cancer. Health Expect 2004;7:104-14.

32. Guest G, Bunce A, Johnson L. How many interviews are enough? An experiment with data saturation and variability. Field Methods 2006;18:59-82.

33. Hsieh HF, Shannon SE. Three approaches to qualitative content analysis. Qual Health Res 2005;15:1277-88.

34. Kunneman M, Engelhardt EG, Ten Hove FL, et al. Deciding about (neo-) adjuvant rectal and breast cancer treatment: missed opportunities for shared decision making. Acta Oncol 2016;55:134-9.

35. Shay LA, Lafata JE. Where is the evidence? A systematic review of shared decision making and patient outcomes. Med Decis Making 2015;35:114-31.

36. Kasper J, Heesen C, Kopke S, et al. Patients' and observers' perceptions of involvement differ. Validation study on inter-relating measures for shared decision making. PLOS ONE 2011;6:e26255

37. Ford S, Schofield T, Hope T. Observing decision-making in the general practice consultation: who makes which decisions? Health Expect 2006;9:130-7

38. Couet N, Desroches S, Robitaille H, et al. Assessments of the exten to which health-care providers involve patients in decision making: a systematic review of studies using the OPTION instrument. Health Expect 2015;18:542-61.

39. Mulley AG, Trimble C, Elwyn G. Stop the silent misdiagnosis: patients' preferences matter. BMJ 2012;345:e6572.

40. Joseph-Williams N, Elwyn G, Edwards A. Knowledge is not power for patients: a systematic review and thematic synthesis of patient-reported barriers and facilitators to shared decision making Patient Educ Couns 2014;94:291-309.

41. Street RL Jr, De Haes HC. Designing a curriculum for communication skills training from a theory and evidence-based perspective. Patient Educ Couns 2013;93:27-33. 